\title{
Development and validation of an UV-Vis spectrophotometric method for the quantification of oclacitinib in capsule formulation
}

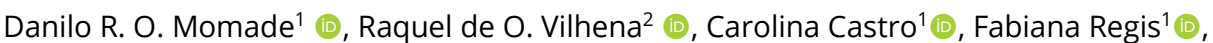
Karime Z. A. Domingues ${ }^{1}$ (D), Laís S. Schlichta ${ }^{1}$ (D), Alexandre de F. Cobre ${ }^{1}$ (D), Roberto Pontarolo*2 (D)

${ }^{1}$ Programa de Pós-graduação em Ciências Farmacêuticas, Universidade Federal do Paraná (UFPR), Curitiba, PR, Brasil ${ }^{2}$ Departamento de Farmácia, Universidade Federal do Paraná (UFPR), Curitiba, PR, Brasil

*Corresponding author: pontarolo@ufpr.br

\begin{abstract}
Objective. The aim of this study was the development and validation of an UV-Vis spectrophotometric method for the quantification of oclacitinib in commercial capsule formulation since pharmacopeias have not yet provided an official monograph for this drug. Methods. The parameters linearity, limit of detection, limit of quantitation, specificity, precision, accuracy, and robustness were determined according to Brazilian and international guidelines. Results. Linearity was determined for the analytical range of $5-15 \mu \mathrm{g} / \mathrm{mL}$, and a limit of detection of $1.18 \mu \mathrm{g} / \mathrm{mL}$ and limit of quantification of $3.58 \mu \mathrm{g} / \mathrm{mL}$ were obtained. The method was selective and the precision was demonstrated through repeatability and intermediate precision, with relative standard deviations of $1.96 \%$ and $1.78 \%$, respectively. In its turn, accuracy presented recovery percentages of $98.32-100.91 \%$. All robustness and sample stability ( $48 \mathrm{~h}$ at $25^{\circ} \mathrm{C}$ ) results revealed no statistical variation among the groups. Conclusions. The presented method is suitable for the quantification of oclacitinib in commercial capsule formulation.
\end{abstract}

Keywords: Analytical validation. Oclacitinib. UV-Vis spectrophotometric.

\section{How to cite}

Momade DRO, Vilhena RO, Castro C, Regis F, Domingues KZA, Schlichta LS, Cobre AF, Pontarolo $R$. Development and validation of an UV-Vis spectrophotometric method for the quantification of oclacitinib in capsule formulation. Rev Ciênc Farm Básica Apl. 2021;42:e712.

https://doi.org/10.4322/2179-443X.0712

\section{INTRODUCTION}

Oclacitinib (OCL) or trans-N-methyl-4-(methyl-7H-pyrrolo[2,3-d]pyrimidin-4-ylamino)cyclohexanemethanesulfonamide (Figure 1) is a Janus Kinase (JAK) inhibitor (JAK1 preferentially) that blocks the signaling of proinflammatory cytokines. It is used for allergic responses and other hypersensitive diseases, such as pruritus and atopic dermatitis (AD) in dogs and cats ${ }^{1}$. This substance is currently not approved for use in humans, but it is available for veterinary use and is provided as coated tablets or capsule formulations from compounding pharmacies ${ }^{1}$.

\section{Financial support: None.}


<smiles>CNS(=O)(=O)CC1CCC[C@H](N(C)c2ncnc3[nH]ccc23)C1</smiles>

Figure 1. Chemical structure of OCL. Conjugated double bonds are highlighted in red.

AD has a prevalence of 3-15\% in the dog population and represent $3-58 \%$ of dogs with diagnosed skin disease ${ }^{2-4}$. The pathogenesis of this disease is complex and involves genetic and environmental factors. The infiltration of the skin by inflammatory cells and the production of cytokines due to allergens from food and microbial or insect sources is one of the mechanisms of $A D^{5}$. It is a life-long disease that can be controlled, but rarely cured. Therefore, rational clinical management of $A D$ is necessary ${ }^{6}$.

$O C L$ has a good safety profile in the treatment of $A D$, in addition to effectiveness and fast action ${ }^{7}$. The initial dosage is $0.4-0.6 \mathrm{mg} / \mathrm{kg}$ taken orally twice a day, but after two weeks it can be reduced to once daily ${ }^{8-10}$. The adverse effects are uncommon, but include anorexia, vomiting and diarrhea ${ }^{8-12}$.

The quality control of medicines involves a series of procedures that are carried out to ensure that the products are not released for commercialization or distribution, until their quality is considered satisfactory. Among the tests performed, quantification of the drug in the pharmaceutical dosage form stands out ${ }^{13,14}$.

Although OCL is already used in clinical practice, there are no data on this drug in official monographs, and there are no methods for the quantification of $\mathrm{OCL}$ in pharmaceutical dosage forms. Thus, there is a need to develop an accurate, precise and robust method for a suitable quality control in manipulated formulas. The present work reports the development and validation of an UV-Vis spectrophotometric method for the quantification of OCL in commercial capsule formulation manipulated.

\section{MATERIAL AND METHODS}

\section{Chemicals}

OCL capsules ( 5 mg), OCL maleate (Cayman Chemicals, Michigan, USA; standard reference), and a matrix (mixture of excipients) were kindly donated by a local compounding pharmacy (Curitiba, Brazil). Ultrapure water was obtained from a Milli-Q® Gradient A10 purification system (Millipore, Milford, USA). High-performance liquid chromatography grade methanol was purchased from Honeywell Riedel-de-Haën (Seelze, Germany) and Tedia (Fairfield, USA).

\section{Equipment and instrumental conditions}

An UV-Vis spectrophotometer Agilent 8453 (Santa Clara, USA) and a quartz cuvette (with an optical path length of $1 \mathrm{~cm}$ ) were used to perform all absorbance analyses at $287 \mathrm{~nm}$. The spectral range was from $200 \mathrm{~nm}$ to $900 \mathrm{~nm}$. 


\section{Standard solutions and calibration curve}

A stock solution was prepared in triplicate at $1 \mathrm{mg} / \mathrm{mL}$ using methanol as a diluent and stored at $-40^{\circ} \mathrm{C}$ in a freezer (Thermo Fisher Scientific, model ULT2140-5-A40, Waltham, USA). Working standard solutions were freshly prepared every day from the stock solution for each experiment, through appropriate dilution with methanol to achieve concentrations of 5, 7.5, $10,12.5$ and $15 \mu \mathrm{g} / \mathrm{mL}$ (calibration curve).

\section{Sample preparation}

For the prepare of the sample solutions, the content of 10 capsules was transferred to a mortar and homogenized with a pestle. The mass corresponding to its medium weight was then dispersed in methanol, using an unfilled $25 \mathrm{~mL}$ volumetric flask. The solution was kept in an ultrasonic bath (Branson, model 5510R-DTH, St. Louis, USA) for $15 \mathrm{~min}$ at $25^{\circ} \mathrm{C}$. The volume was completed to $25 \mathrm{~mL}$ with methanol, and the solution was centrifuged for $4 \mathrm{~min}$ at $4000 \mathrm{rpm}$ (Eppendorf, model $5810 \mathrm{R}$, Hamburg, Germany). Lastly, $0.5 \mathrm{~mL}$ was transferred to a $10 \mathrm{~mL}$ volumetric flask and completed with methanol, resulting in a theoretical concentration of $10 \mu \mathrm{g} / \mathrm{mL}$.

\section{Determination of maximum absorption $\lambda_{\max }$}

A working standard solution at $10 \mu \mathrm{g} / \mathrm{mL}$ was scanned from 200 to $400 \mathrm{~nm}$ with an UV-Vis spectrophotometer and an UV spectrum was obtained. Methanol was used as the blank.

\section{Analytical Validation}

Method validation was performed according to Brazilian and international guidelines ${ }^{15,16}$.

\section{Linearity}

Linearity was established from 3 individual analytical curves, prepared by OCL stock solutions, obtaining 5 different concentrations $(5,7.5,10,12.5$ and $15 \mu \mathrm{g} / \mathrm{ml})$. The UV absorbance was measured at $287 \mathrm{~nm}$. The limit of detection (LOD) and limit of quantification (LOQ) were calculated as described below:

$$
\begin{aligned}
& L O D=\frac{3.3 \times \text { standard deviation of regression line }}{\text { slope from regressionline }} \\
& L O Q=\frac{10 \times \text { standard deviation of regression line }}{\text { slope from regressionline }}
\end{aligned}
$$

The linearity of the model was evaluated using the least squares regression model. To validate the regression model, the following tests were evaluated: ANOVA, $t$ test, $R^{2}$, Pearson correlation, Durbin-Watson test, homogeneity, and normality of the residues.

\section{Specificity}

To survey the specificity of the method, the test was carried out using only excipients. The absorbance of an OCL standard solution $(5 \mu \mathrm{g} / \mathrm{mL})$ was compared with the absorbance of a matrix (excipients) solution composed of a mixture of starch, talc, magnesium stearate, sodium lauryl sulfate and colloidal silicon dioxide. The matrix solution was obtained as a sample preparation. Spectra for the matrix, blank, and sample were also compared. The method was applied to determine if any component of the formulation could generate a response or a read with an absorption band similar to the drug. 


\section{Repeatability and Intermediate Precision}

The precision was determined according to the repeatability (intra-day) and intermediate precision (inter-day) parameters. Under the same conditions, 6 sample solutions $(10 \mu \mathrm{g} / \mathrm{mL})$ were prepared as described in the "Sample preparation" section and assayed by the UV method at $287 \mathrm{~nm}$ (read in triplicate). This procedure was repeated by a different analyst on a non-consecutive day. Sample concentration and relative standard deviations (RSD) were calculated. Intermediate precision data was evaluated by the Shapiro-Wilk test, to evaluate the normality of data distribution ( $p>0.05)$, and then the F-test and the Student's t-test.

\section{Accuracy}

Accuracy was determined by recovery. Accurately weighed amounts of 4, 5 and $6 \mathrm{mg}$ of $\mathrm{OCL}$ reference standard were added to the matrix (excipients) equivalent to a capsule content (130 mg). Then, they were submitted in triplicate to the sample preparation procedure resulting in concentrations of 8,10 and $12 \mu \mathrm{g} / \mathrm{mL}$. After UV analysis, the experimental concentrations and relative errors were calculated as described below:

$$
E R(\%)=\frac{(\text { measured value }- \text { nominal value })}{\text { nominal value }} \times 100
$$

\section{Robustness}

To verify the robustness of the sample preparation method, samples (OCL plus excipients at the nominal dosage) were prepared in triplicate at different ultrasound times $(13,15$ and $17 \mathrm{~min}$ ) and with two different manufacturers of methanol. Robustness was assessed by applying factorial ANOVA to analyze the effect of ultrasound time variation and the MannWhitney test was used to evaluate methanol manufacturer variation.

\section{Stability}

The stability assay was performed at room temperature $\left( \pm 25^{\circ} \mathrm{C}\right)$ and under cooling condition $\left(2{ }^{\circ} \mathrm{C}-8{ }^{\circ} \mathrm{C}\right)$. The UV-Vis absorbance of the $\mathrm{OCL}$ samples $(10 \mu \mathrm{g} / \mathrm{mL})$ and $\mathrm{OCL}$ standard solutions $(10 \mu \mathrm{g} / \mathrm{mL})$ was obtained at 0,24 and $48 \mathrm{~h}$ for each temperature condition. The Mauchly sphericity (stability) test was applied for stability evaluation.

\section{Statistical analysis}

Results were presented as mean \pm standard deviation (SD). Statistical analysis was performed using the SPSS 20 program (USA, New York), and p values $<0.05$ were considered statistically significant.

\section{RESULTS AND DISCUSSION}

A solubility test of OCL with different solvents was previously performed (data not shown). OCL was very slightly soluble in water and acetonitrile, slightly soluble in ethanol and very soluble in methanol. Therefore, methanol was chosen as the solvent for the preparation of the standard and sample.

OCL has conjugated double bonds that are responsible for UV absorption (Figure 1). The UV-Vis spectrum showed that $287 \mathrm{~nm}$ was the ideal wavelength; therefore, this wavelength was used for all analyses (Figure 2). 


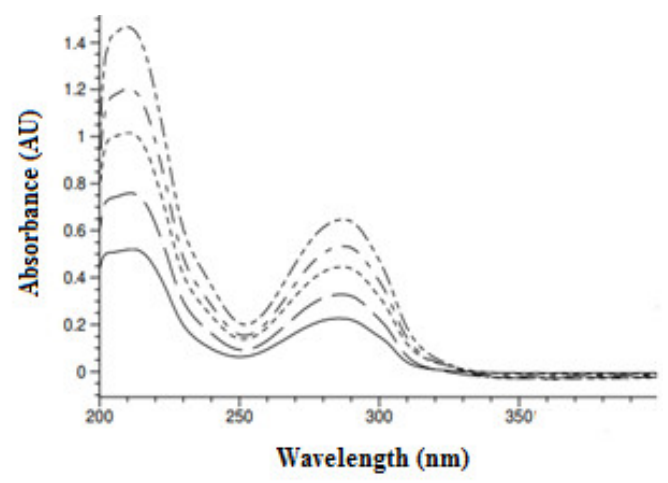

Figure 2. UV spectra of OCL standards at different concentrations

The correlation coefficient $\left(R^{2}\right)$ obtained for the linearity was 0.990 , demonstrating that $99 \%$ of the concentration variance is predicted by the absorbance of OCL. These values were determined from the mean curve of three analytical curves (Figure 3).

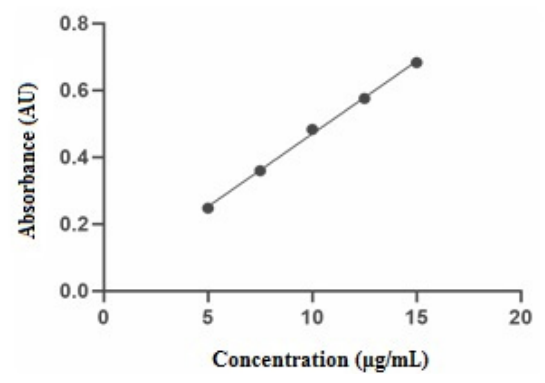

Figure 3. Mean analytical curve of OCL.

Pearson's correlation test was applied between the two variables (concentration and absorbance), both of which were highly correlated $(p=0.000$ and $r=0.995)$. Then, the quality of the was determined by the ANOVA test and a significant $p$ value $(p=0.000)$ was obtained.

The Student's t-test was also applied to analyze the importance of the regression equation coefficients, in which the linear coefficient was statistically equal to zero $(p=0.015)$. Therefore, the equation was defined by $y=0.043 x+0.035$.

Then, the Durbin Watson's test was applied to analyze the independence of experimental errors, proving the absence of correlation (value of 1.839 , with a maximum acceptable value of 2.5. In addition, the standardized residues had normal distribution (mean $=0$ and $S D=1$ ) and presented homogeneity (Figure 4).

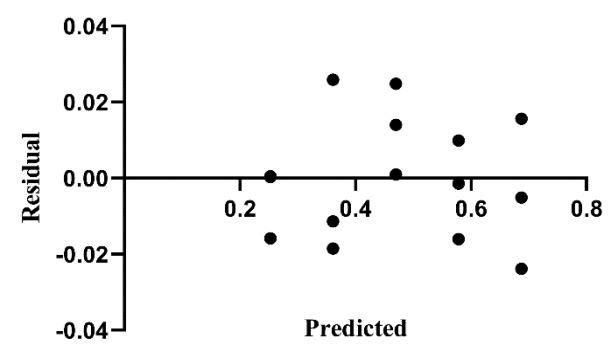

Figure 4. Residual plot from the regression model 
Lastly, the limit of detection was found to be $1.18 \mu \mathrm{g} / \mathrm{mL}$ and the limit of quantification was found to be $3.58 \mu \mathrm{g} / \mathrm{mL}$.

The spectrum for the mixture of excipients (Figure 5) showed no absorption at $287 \mathrm{~nm}$. Thus, the method specificity in the presence of excipients was demonstrated as well as its suitability for the determination of OCL in pharmaceutical formulations.

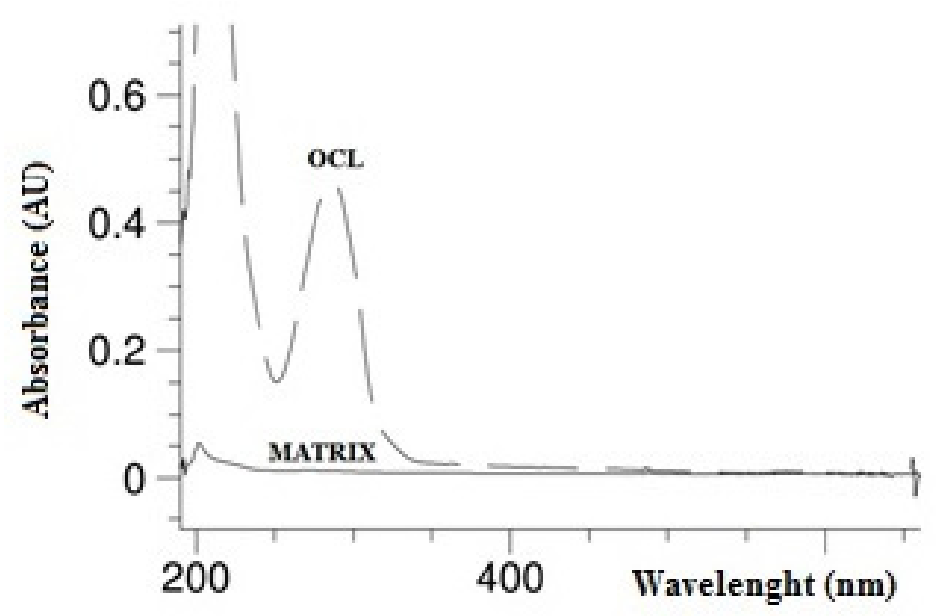

Figure 5. UV-Vis absorbance spectra of the mixture of excipients and OCL standard solution.

The repeatability and intermediate precision results are summarized in Table 1. For both parameters, the values obtained for the RSD were less than $2 \%$, demonstrating adequate repeatability for the analytical method ${ }^{15}$. In addition, the Shapiro-Wilk test indicated that the data had a normal distribution ( $p=0.138$ ), which proves the adequacy of the Student's T test applied. The intermediate precision analysis showed no significant difference between the groups $(p>0,05)$, indicating the precision of the method.

Table 1. Experimental results from repeatability and intermediate precision assays $(n=6)$.

\begin{tabular}{cccccc}
\hline Days & Analyst & $\begin{array}{c}\text { Mean } \\
\text { Concentratio } \\
\mathbf{n}(\boldsymbol{\mu g} / \mathbf{m L})\end{array}$ & SD $(\mu \mathrm{g} / \mathbf{m L})$ & RSD (\%) & p-value \\
\hline Day 1 & 1 & 11.36 & 0.22 & 1.96 & $0.1405^{*}$ \\
Day 2 & 2 & 11.26 & 0.20 & 1.78 & \\
\hline
\end{tabular}

* no significant difference by Student's t-test. SD, standard deviation; RSD, relative standard deviation.

Accuracy recovery was $98.33 \%, 100.91 \%$ and $98.32 \%$ respectively for the 8,10 and $12 \mu \mathrm{g} / \mathrm{mL}$ concentrations, with a relative error $<2 \%$. This data indicates an appropriate accuracy according to Brazilian guidelines ${ }^{15}$.

Robustness was validated by varying the ultrasound time and using different manufacturer of methanol. Neither variations affected the results of samples in concentrations of $10 \mu \mathrm{g} / \mathrm{mL}$. No significant difference was obtained by using one-way ANOVA $(p=0.767)$ for ultrasound time, or by using Mann-Whitney test $(p=0.100)$ for different methanol manufacturers.

Lastly, the stability of the OCL sample and standards, in cool and at room temperature, was demonstrated for 0,24 and $48 \mathrm{~h}$, with no significant difference between the analyzed times, with $p$ value $>0,05$ as demonstrated by Table 2 . 
Table 2. Stability assays of standard and sample solutions of OCL at $10 \mu \mathrm{g} / \mathrm{mL}$.

\begin{tabular}{|c|c|c|c|c|c|}
\hline & & Hours & $\begin{array}{c}\text { Mean Concentration } \\
(\mu \mathrm{g} / \mathrm{mL})\end{array}$ & $S D(\mu \mathrm{g} / \mathrm{mL})$ & p-value \\
\hline \multirow{6}{*}{ Standard } & \multirow{3}{*}{$\begin{array}{l}\text { Room temperature } \\
\qquad(\mathrm{n}=3)\end{array}$} & 0 & 10.10 & 0.0882 & \multirow{3}{*}{$0.245^{*}$} \\
\hline & & 24 & 10.67 & 0.0825 & \\
\hline & & 48 & 10.55 & 0.1635 & \\
\hline & \multirow{3}{*}{$\begin{array}{l}\text { Cool conditions } \\
\qquad(\mathrm{n}=3)\end{array}$} & 0 & 10.10 & 0.0882 & \multirow{3}{*}{$0.756 *$} \\
\hline & & 24 & 9.69 & 0.0708 & \\
\hline & & 48 & 10.37 & 0.1661 & \\
\hline \multirow{6}{*}{ Sample } & \multirow{4}{*}{$\begin{array}{l}\text { Room temperature } \\
\qquad(\mathrm{n}=3)\end{array}$} & 0 & 10.32 & 0.2624 & \multirow{3}{*}{$0.521 *$} \\
\hline & & 24 & 10.43 & 0.2054 & \\
\hline & & 48 & 10.49 & 0.2279 & \\
\hline & & 0 & 10.67 & 0.2659 & \multirow{3}{*}{$0.382^{*}$} \\
\hline & \multirow{2}{*}{$\begin{array}{l}\text { Cool conditions } \\
\qquad(n=3)\end{array}$} & 24 & 9.84 & 0.2272 & \\
\hline & & 48 & 9.84 & 0.2058 & \\
\hline
\end{tabular}

* Mauchly's Test of Sphericity. SD, standard deviation; RSD, relative standard deviation.

The developed spectrophotometric method was validated according to Brazilian and international guidelines. It is therefore presented as a fast, inexpensive and effective method for quantifying $\mathrm{OCL}$ in commercial capsule formulation.

\section{ACKNOWLEDGMENTS}

This study was financed in part by the Coordenação de Aperfeiçoamento de Pessoal de Nível Superior - Brazil (CAPES) - Finance Code 001. The authors would like to thank the Secretariat of Science. Technology and Higher Education (SETI-PR) for the financial support for laboratory infrastructure.

\section{REFERENCES}

1. European Medicines Agency. Apoquel: summary of opinion; 2013 [cited 2019 Feb 5]. Available from: https://www.ema.europa.eu/en/documents/smop-initial/cvmp-summary-positive-opinionapoquel_en.pdf

2. Hill PB, Lo A, Eden CA, Huntley S, Morey V, Ramsey S, Richardson C, Smith DJ, Sutton C, Taylor MD, et al. Survey of the prevalence, diagnosis and treatment of dermatological conditions in small animals in general practice. Vet Rec. 2006;158(16):533-9. http://dx.doi.org/10.1136/vr.158.16.533. PMid:16632525.

3. Hillier A, Griffin CE. The ACVD task force on canine atopic dermatitis (I): incidence and prevalence. Vet Immunol Immunopathol. 2001;81(3):147-51. http://dx.doi.org/10.1016/S0165-2427(01)00296-3. PMid:11553375.

4. Nødtvedt A, Egenvall A, Bergvall K, Hedhammar A. Incidence of and risk factors for atopic dermatitis in a Swedish population of insured dogs. Vet Rec. 2006;159(8):241-6. http://dx.doi.org/10.1136/vr.159.8.241. PMid:16921013.

5. Marsella R, Sousa CA, Gonzales AJ, Fadok VA. Current understanding of the pathophysiologic mechanisms of canine atopic dermatitis. J Am Vet Med Assoc. 2012;241(2):194-207. http://dx.doi.org/10.2460/javma.241.2.194. PMid:22765366.

6. Lopes NL, Campos DR, Machado MA, Alves MSR, de Souza MSG, da Veiga CCP, Merlo A, Scott FB, Fernandes Jl. A blinded, randomized, placebo-controlled trial of the safety of oclacitinib in cats. BMC Vet Res. 2019;15(1):137. http://dx.doi.org/10.1186/s12917-019-1893-x. PMid:31068210.

7. Saridomichelakis MN, Olivry T. An update on the treatment of canine atopic dermatitis. Vet J. 2016;207:29-37. http://dx.doi.org/10.1016/j.tvjl.2015.09.016. PMid:26586215. 
8. Cosgrove SB, Wren JA, Cleaver DM, Walsh KF, Follis SI, King VI, Tena JS, Stegemann MR. A blinded, randomized, placebo-controlled trial of the efficacy and safety of the Janus kinase inhibitor oclacitinib (Apoquel ${ }^{\circledR}$ ) in client-owned dogs with atopic dermatitis. Vet Dermatol. 2013;24(6):58797, e141-2. http://dx.doi.org/10.1111/vde.12088. PMid:24581322.

9. Cosgrove SB, Wren JA, Cleaver DM, Martin DD, Walsh KF, Harfst JA, Follis SL, King VL, Boucher JF, Stegemann MR. Efficacy and safety of oclacitinib for the control of pruritus and associated skin lesions in dogs with canine allergic dermatitis. Vet Dermatol. 2013;24(5):479-87. http://dx.doi.org/10.1111/vde.12047. PMid:23829933.

10. Gadeyne C, Little P, King VL, Edwards N, Davis K, Stegemann MR. Efficacy of oclacitinib (Apoquel®) comparedwith prednisolone for the control of pruritus and clinical signs associated with allergic dermatitis in client-owned dogs in Australia. Vet Dermatol. 2014;25(6):512-8, e86. http://dx.doi.org/10.1111/vde.12166. PMid:25109820.

11. Cosgrove SB, Cleaver DM, King VL, Gilmer AR, Daniels AE, Wren JA, Stegemann MR. Long term compassionate use of oclacitinib in dogs with atopic and allergic skin disease: safety, efficacy and quality of life. Vet Dermatol. 2015;26(3):171-9, e35. http://dx.doi.org/10.1111/vde.12194. PMid:25688708.

12. Little PR, King VL, Davis KR, Cosgrove SB, Stegemann MR. A blinded, randomized clinical trial comparing the efficacy and safety of oclacitinib and ciclosporin for the control of atopic dermatitis in client-owned dogs. Vet Dermatol. 2015;26(1):23-30, e7-8. http://dx.doi.org/10.1111/vde.12186. PMid:25496303.

13. ANVISA [Internet]. Farmacopeia Brasileira. 6. ed. Brasília: ANVISA; 2019. Vol. 1.

14. Brasil. Agência Nacional de Vigilância Sanitária. Resolução RDC n 301 de 21 de agosto de 2019. Diário Oficial da União [Internet]; Brasília; 22 ago 2019. [cited 2020 dez 07] Available from: http://antigo.anvisa.gov.br/documents/10181/5389382/\%286\%29RDC_301_2019_COMP.pdf/7d991c 04-e7a1-4957-aed5-3689c62913b2.

15. Brasil. Agência Nacional de Vigilância Sanitária. Resolução RDC nº 166 de 24 de julho de 2017. Diário Oficial da União [Internet]; Brasília; 25 jul 2019. [cited 2020 mar 10] Available from: http://antigo.anvisa.gov.br/documents/10181/2721567/RDC_166_2017_COMP.pdf/d5fb92b3-6c6b4130-8670-4e3263763401.

16. International Conference on Harmonization [Internet]. Validation of analytical procedures: text and methodology Q2(R1). 2005; [cited 2019 Feb 4]. Available from:

http://academy.gmpcompliance.org/guidemgr/files/Q2(R1).PDF

\section{Authors' contributions}

DROM: Conceptualization, Methodology, Investigation, Formal analysis, Validation, Original draft preparation; ROV: Conceptualization, Project administration, Methodology, Investigation, Formal analysis, Original draft preparation; CC: Visualization, Investigation, Formal analysis, Validation, Original draft preparation; FR: Formal analysis, Validation, Original draft preparation, Formal analysis, Validation; KZAD: Writing- Reviewing and Editing, Validation; LSS: Investigation, Review \& Editing; AFC: Formal analysis, Review \& Editing; RP: Conceptualization, Resources, Original draft preparation, Funding acquisition, Supervision. 